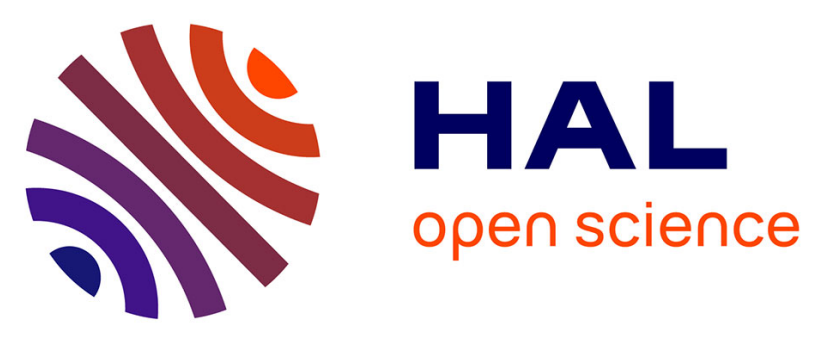

\title{
Recommendation of the RILEM TC 236-BBM: characterisation testing of hemp shiv to determine the initial water content, water absorption, dry density, particle size distribution and thermal conductivity
} Sofiane Amziane, Florence Collet, Mike Lawrence, Camille Magniont, Vincent

Picandet, Mohammed Sonebi

\section{To cite this version:}

Sofiane Amziane, Florence Collet, Mike Lawrence, Camille Magniont, Vincent Picandet, et al.. Recommendation of the RILEM TC 236-BBM: characterisation testing of hemp shiv to determine the initial water content, water absorption, dry density, particle size distribution and thermal conductivity. Materials and structures, 2017, 50 (3), 10.1617/s11527-017-1029-3 . hal-01523118

HAL Id: hal-01523118

https://hal-univ-rennes1.archives-ouvertes.fr/hal-01523118

Submitted on 4 Mar 2019

HAL is a multi-disciplinary open access archive for the deposit and dissemination of scientific research documents, whether they are published or not. The documents may come from teaching and research institutions in France or abroad, or from public or private research centers.
L'archive ouverte pluridisciplinaire HAL, est destinée au dépôt et à la diffusion de documents scientifiques de niveau recherche, publiés ou non, émanant des établissements d'enseignement et de recherche français ou étrangers, des laboratoires publics ou privés.

\section{(ㄷ)(1) $\$$}

Distributed under a Creative Commons Attribution - NonCommerciall 4.0 International 


\title{
Recommendation of the RILEM TC 236-BBM: characterisation testing of hemp shiv to determine the initial water content, water absorption, dry density, particle size distribution and thermal conductivity
}

\author{
Sofiane Amziane $(\mathbb{D} \cdot$ Florence Collet $\cdot$ Mike Lawrence $\cdot$ \\ Camille Magniont • Vincent Picandet $\cdot$ Mohammed Sonebi
}

Received: 13 November 2016/ Accepted: 28 March 2017/Published online: 18 April 2017

(C) RILEM 2017

\begin{abstract}
This recommendation is the outcome of research conducted by a working group within the RILEM Technical Committee 236-BBM 'Bio-aggregate-based building Materials'. The work of the group related to the study of construction materials made from plant particles. The major raw material utilised being renewable, recyclable and easily available plant particles. These particles are obtained from the
\end{abstract}

This recommendation was prepared by a working group within RILEM TC-236 coming from eight laboratories: Institut Pascal (Clermont University), BRE Centre for Innovative

Construction Materials (University of Bath), IRDL (Université de Bretagne Sud), DGCB (ENTPE, Lyon), LGCGM (Rennes 1), LMDC (Université de Toulouse/UPS/INSA), ComblouxAgro ressource (Université de Liège). The draft was approved by the all TC members of RILEM TC 236-BBM (See the list below). The contributions by the other contributors (cited below), to the work of the TC are gratefully acknowledged.

TC 236 BBM Members:

Chairman: Sofiane AMZIANE, Institut Pascal, Clermont Université, France.

Secretary: Florence COLLET, Université de Rennes 1, LGCGM, France.

TC Members: Laurent ARNAUD, Ecole Nationale Supérieure d'Arts et Métiers, ENSAM Cluny, France. Laëtitia BESSETTE, Centre Technique Louis VICAT, L'Isle d'Abeau, France. Paulien De Bruijn, Lund University, Faculty of Engineering (LTH), Dept of Building Materials, Lund, Sweden. Gilles ESCADEILLAS, Université de Toulouse, UPS, INSA, LMDC, France. Etienne GOURLAY, CETE de l'Est Laboratoire Régional de Strasbourg, France. Christophe LANOS, Université de Rennes 1, LGCGM, France. Mike processing of hemp, flax, miscanthus, pine, maize, sunflower, bamboo and other plants. In this report, the outcome of the Round Robin Testing is centred on hemp because hemp shiv is the bio-aggregate that is the most widely used in building materials and the most studied in the literature. The first round robin test of the TC-BBM published in the State of The Art Report of Technical Committee 236-BBM 'Bioaggregate-based building Materials' was carried out

LAWRENCE, University of Bath, BRE Centre for Innovative Construction Materials, UK. Camille MAGNIONT, Université de Toulouse, UPS, INSA, LMDC, France. Sandrine MARCEAU, Université Paris-Est, IFSTTAR, France. Sara PAVÍA, Department of Civil Engineering, Trinity College, Ireland. Ulrike PETER, Lhoist, Lhoist Recherche et Développement S.A., Belgium. Vincent PICANDET, IRDL, Université de Bretagne Sud, France. Mohammed SONEBI, School of Natural and Built Environment, Queen's University Belfast, UK. Pete WALKER, University of Bath, BRE Centre for Innovative Construction Materials, UK.

Other contributors: Thibaut COLINART, IRDL, Université de Bretagne Sud, France. Guillaume DELANNOY, Université Paris-Est, IFSTTAR, France. Yunhong JIANG, University of Bath, BRE Centre for Innovative Construction Materials, UK. César NIYIGENA, Institut Pascal, Clermont Université, France. Vincent NOZAHIC, Institut Pascal, Clermont Université, France. Sylvie PRETOT, Université de Rennes 1, LGCGM, France. Pierre TRONET, IRDL, Université de Bretagne Sud, France. Samuel DUBOIS, Université de Liège (Ulg), Gembloux Agro-Bio Tech, Belgique. Harald Garecht, Universität Stuttgart, Institut für Werkstoffe im Bauwesen (IWB), Stuttgart, Deutschland. André Klatt, Universität Stuttgart, Institut für Werkstoffe im Bauwesen (IWB), Stuttgart, Deutschland. 
to compare the protocols in use by the different laboratories (labs) to measure initial water content, bulk density, water absorption, particle grading and thermal conductivity. The aim was to define a standardised characterisation protocol developed from those used by the different labs. The different methodologies used by 7 labs constitute a set of statistically representative data which have been analysed to develop this recommendation for the characterisation of hemp shiv.

Keywords Hemp shiv - Initial water content - Water absorption · Dry density · Particle size distribution . Thermal conductivity

\section{Scope}

These RILEM Technical Recommendations aim to give a description of methods to measure initial water content, bulk density, water absorption, particle size grading and thermal conductivity of bio-aggregate. The characterisation protocol has been derived from those used by the different participating labs of the TC 236-BBM [1-3]. This recommendation is based on the first Round Robin Test, which was carried out on one variety of hemp shiv [1-3]. These testing procedures may also be applied to other plant aggregates obtained from the processing of flax, miscanthus, pine, maize,

S. Amziane ( $\square)$

CNRS, Institut Pascal, UMR 6602, Université Clermont

Auvergne, Clermont-Ferrand, France

e-mail: sofiane.amziane@uca.fr

F. Collet

LGCGM, Université Rennes 1, Rennes, France

M. Lawrence

BRE Centre for Innovative Construction Materials,

University of Bath, Bath, UK

C. Magniont

Université de Toulouse, UPS, INSA, LMDC, Toulouse, France

V. Picandet

IRDL, Université de Bretagne Sud, 56100 Lorient, France

M. Sonebi

School of Natural and Built Environment, Queens

University of Belfast, Belfast, UK sunflower, bamboo, coconut, rice husk, typha, date palm and other plant aggregates.

\section{Significance and use}

This recommendation focuses on bio-based aggregates produced from the stem of plants cultivated either for their fibres (hemp, flax, straw, coconut, etc.) or for their seeds (oleaginous flax, sunflower, etc.) [4-6]. The nature of the structure of the stem of plants such as hemp produce aggregate (shiv) which is generally malleable, elongated and highly porous with a low apparent density [4-6]. They are very different from the traditional aggregates typically used in the production of concrete, for which there exist standards and techniques to be used for the characterisation. Amongst these bio-based aggregates, hemp shiv (the woody core of the stem of the hemp plant) is probably the most widely used as alternative or eco-friendly building material in Europe and is also representative of most of the aggregate made from the stem because hemp is an annual plant (around 4 months for harvesting) requiring no herbicides and no pesticides in growth [4-6]. This is usually mixed with a limebased binder to produce bio-based building materials which is known as hemp concrete. These bio-aggregate based concretes with lime-based binders are mainly used in construction for roof insulation, filling of self-bearing structure, realisation of insulating screeds and decorative [4-6].

Hemp shiv aggregates derive from the inner part of the fragmented stalk of the hemp plant, as a co-product of the mechanical defibering process (shiv represents around $40-60 \%$ by mass) [6]. Hemp shiv aggregates can have different origins, can be grown under different climatis conditions, be harvested at different stages and using different harvesting methods so their microstructure can differ considerably. Historically, hemp shiv aggregates were a by-product of the hemp fibre industry [4-6]. In the recent years, hemp shiv aggregates have predominantly been used as aggregates to make hemp concrete, and the price of mineral aggregates is steadily increasing as resources become less readily available. The characterisation of these aggregates, however, which is crucial to a proper understanding of the quality of the materials in which they are incorporated, requires adaptations to be made to the tests and techniques usually employed for 
mineral aggregates, or developing new characterisation procedures for this kind of plant aggregate.

The first round robin test of the RILEM TC-BBM236 was carried out to compare the protocols to be used by different laboratories. The aim was to define a test method to measure the initial water content and water absorption of bio-aggregates. This first round robin test was carried out with one variety of hemp shiv coming from the same production of a processing factory located in France. Seven laboratories conducted the measurements of water absorption.

Similar to other lignocellulosic materials, hemp shiv is known to present a highly hygroscopic behaviour. The water content of hemp shiv will then be largely influenced by relative humidity of air at the time of bagging or mixing. This property needs to be assessed as it can strongly influence the mix proportioning of hemp-lime and consequently the properties of hardened hemp-lime.

The woody part occupies a largest quantity of hemp stem. Hemp shiv is extracted from this woody part after extraction of hemp fibres. Hemp shiv is a highly porous material which has therefore an excellent capacity to absorb and retain water. Microscopic investigation shows that shiv possesses capillaries of different diameters which are oriented longitudinally. These capillaries are empty in a dry state and the diameters of capillaries range from 10 to $50 \mu \mathrm{m}$ [4-6]. Their complex architecture and microstructure is marked by a multi-scale porosity which exists in order to conduct the necessary fluids for their development (sap and water). Even after cutting and being subjected to different production process, this porosity continues to function and is therefore the main route for absorption of water following the Laplace laws. This absorption occurs mainly through conducting vessels or tracheids before the water spreads to the rest of the cells by diffusion through the cell walls and fractures.

The bulk density of hemp shiv is linked to the porosity of the particles and to the inter-particular porosity. In this round robin test, bulk density of hemp shiv is measured in a cylindrical mould with a loose packing and without compaction. Four laboratories measured it with one mould and at one state (dry state or ambient relative humidity). The other laboratories studied the effect of the size of the mould on bulk density measurement at $23{ }^{\circ} \mathrm{C}$, and relative humidity (RH) at $50 \% \mathrm{RH}$ and also the effect of relative humidity on the bulk density of hemp shiv.

\section{Material and sampling procedure}

When hemp shiv is placed in a container, vibrations induce a segregation of the particles. The finest particles generally move towards the bottom of the container. When shiv is removed piecemeal from a container in order to make a sample, the coarser particles are generally removed first, while the finest remain at the bottom of the container. If the container is made of plastic, this effect is magnified due to electrostatic forces which stick the finest particles to the walls of the container.

To prevent this kind of segregation of the particles when samples are taken, a quartering procedure should be applied (Fig. 1).

\subsection{Equipment required}

- Smooth flat plate.

- Container of 101.

- Sample splitter or spatula.

- Small scoop.

\subsection{Size of sample}

A sample of 101 (around $1 \mathrm{~kg}$ ) of hemp shiv is required for one test of sampling.

3.3 Operating instructions

1. Place all of the hemp shiv on flat and smooth surface (a smooth table for example). Homogenize the shiv (by mixing manually) and place the hemp shiv into a pile.

2. Quarter the pile vertically (divide it manually in two similar separate piles and repeat this procedure to the divided piles). Use a non-cutting blade or a long and straight spatula to separate the piles.

3. Repeat this procedure until you obtain a pile with required quantity to make sample. 
Fig. 1 Sampling procedure for bio-aggregates. Note When this procedure is applied, you cannot obtain an exact given mass. Therefore only upper and lower limit of sample mass should be specified, especially for sampling aimed at the study of granular distribution or of water absorption

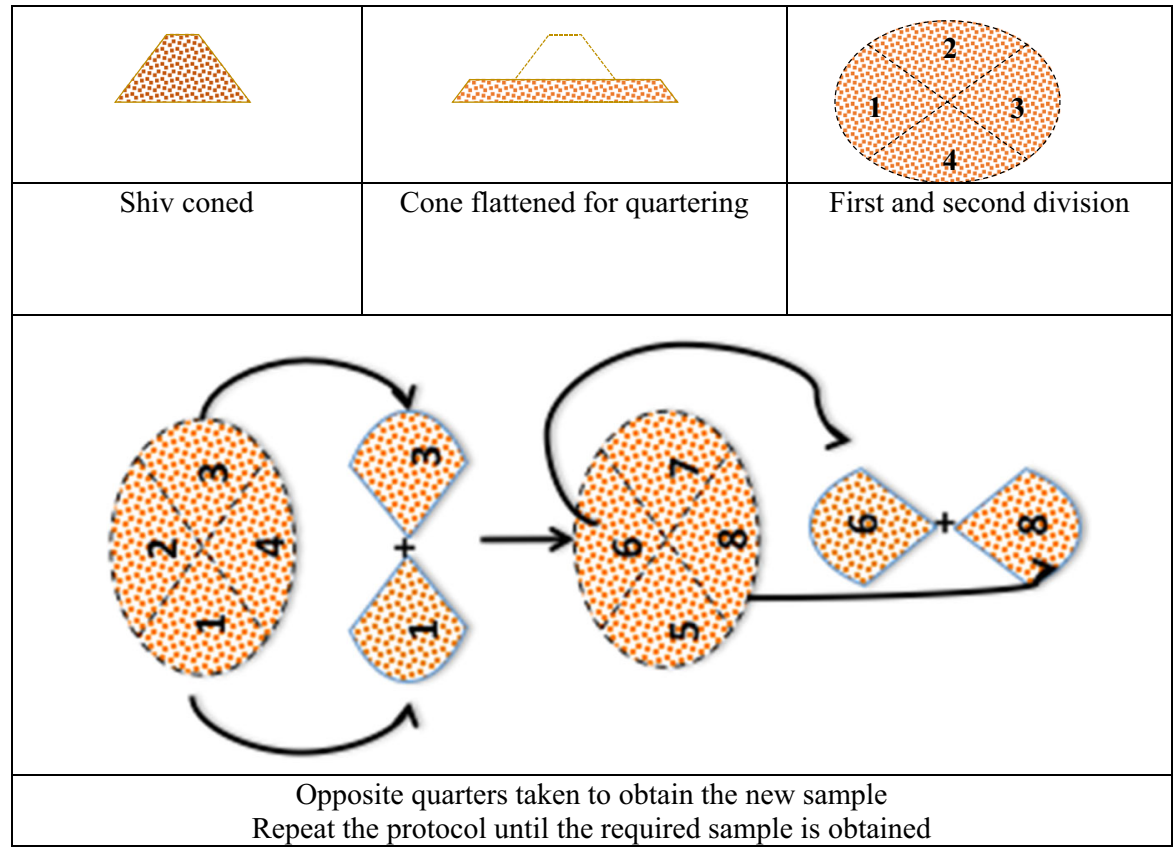

\section{Testing methods}

\subsection{Precision}

For this recommendation, the standard deviation is determined to be used to quantify the amount of variation or dispersion of a set of data values. The standard deviation of data set is the square root of its variance. For a finite set of data, the standard deviation is found by taking the square root of the average of the squared deviations of the values from their average value.

The coefficient of variation (COV) indicates the dispersion of the experimental results; it is calculated by the ratio between the standard deviation and the mean value, in $(\%)$.

\subsection{Initial water content}

The measurement of initial water content consists of weighing aggregates in their initial state and after drying [1].

\subsubsection{Equipment required}

- Balances or scales, accurate to $\pm 0.1 \%$ of test portion mass.
- Small scoop.

- Moulds to take sample of hemp shiv aggregates.

- Ventilated oven, thermostatically controlled to maintain a temperature of $\left(60 \pm 5{ }^{\circ} \mathrm{C}\right)$, or other suitable equipment for drying the bio-aggregates, provided it does not cause any particle size breakdown.

\subsubsection{Size of sample}

A sample of $200 \mathrm{~g}$ of hemp shiv is required to determine the initial water content.

\subsubsection{Operating instructions}

1. After sampling (Fig. 1), weigh the initial mass of aggregates $m_{0}(g)\left(m_{0}>50 \mathrm{~g}\right)$.

2. Dry the material at a temperature between 50 and $60{ }^{\circ} \mathrm{C}$ until constant mass is reached (change in mass of the sample less than $0.1 \%$ over $24 \mathrm{~h}$ ).

3. Weigh the dry mass of aggregates $m_{D}(g)$.

4. Calculate the initial water content with Eq. 1.

$W=\frac{m_{0}-m_{D}}{m_{D}} \times 100$ 
where $W$ is the water content [\%], $m_{0}$ is the mass of the sample $[\mathrm{g}]$ and $m_{D}$ is the mass of dry sample [g].

5. Repeat the test 3 times (with 3 different samples of shiv).

\subsubsection{Precision}

If the coefficient of variation is less than $5 \%$, the mean value is considered to be representative. If not, repeat the protocol again until the statistical test can be validated.

\subsection{Water absorption}

The measurement of water absorption consists in drying aggregates and then calculating their water content at a number of different immersion times [1].

\subsubsection{Equipment required}

- Balances or scales, accurate to $\pm 0.1 \%$ of test portion mass.

- Synthetic or metallic permeable bag (with perforations around $1 \mathrm{~mm}^{2}$ ).

- Common salad spinner.

- Ventilated oven, thermostatically controlled to maintain a temperature of $\left(60 \pm 5^{\circ} \mathrm{C}\right)$, or other suitable equipment for drying the bio-aggregates, provided it does not cause any particle size breakdown.

- Water supply.
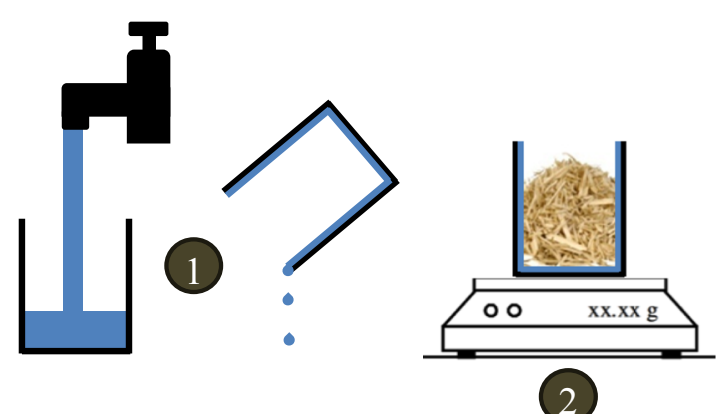

\subsubsection{Size of sample}

A sample of $1 \mathrm{~kg}$ a hemp shiv is required for one test of water absorption.

\subsubsection{Operating instructions}

The water absorption test is illustrated in Fig. 2. The operating instructions are:

1. After sampling (Fig. 1), dry $200 \mathrm{~g}$ of shiv at $60{ }^{\circ} \mathrm{C}$ until the change in mass of the sample is less than $0.1 \%$ over $24 \mathrm{~h}$.

2. Put hemp shiv in a sealed bag or a sealed bucket until equilibrated with room temperature.

3. Place a synthetic or metallic permeable bag (with perforations around $1 \mathrm{~mm}^{2}$ ) in water and ensure a complete wetting.

4. Place the bag in a "salad spinner" and turn the spinner 100 times at approximately 2 rotations per second.

5. Tare the spun permeable bag and note the value in a data sheet.

6. After Sampling (Fig. 1), weigh $25 \mathrm{~g}\left(M_{0}\right)$ of dry hemp shiv in the spun water permeable plastic or metallic bag.

7. Immerse the shiv bag in water for a period of $1 \mathrm{~min}$.

8. Place the bag in a "salad spinner" and turn the spinner 100 times at approximately 2 rotations per second.

9. Weight the spun shiv bag and note the value $M$ (1 min).

10. Repeat steps 6,7 and 8 with the same sample at different immersion times: 15, $240 \mathrm{~min}(4 \mathrm{~h})$ and $2880 \mathrm{~min}(48 \mathrm{~h})$.

Fig. 2 Experimental protocol to measure the water absorption
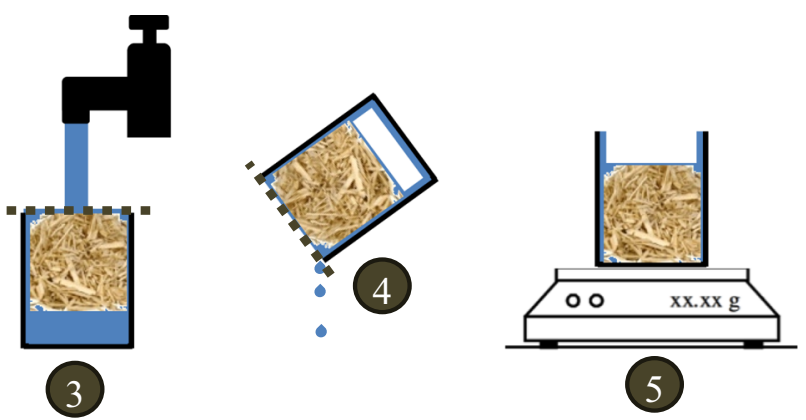
11. Calculate, for each time, the value of absorption (water content) using Eq. 1, and calculate:

- Initial rate of absorption (IRA) which corresponds to $\mathrm{W}$ (1 min).

- $K_{1}$ which correspond to the slope of the curve $\mathrm{W}(\mathrm{t})$ as a function of logarithmic time.

12. Repeat the test 3 times (with 3 different samples of shiv).

\subsubsection{Precision}

Considering the value of absorption for each time, if the coefficient of variation is less than $5 \%$, the mean value is considered to be representative. If not, repeat the protocol again until the statistical test can be validated.

\subsubsection{Report}

The report should include:

- Identification of test sample.

- Date of test.

- Data related to the drying of the sample.

- Description of the protocol with description of the bag giving the size of the sample and its volume.

- picture of the salad spinner.

- bulk density of shiv in a dry state and the bulk density of the sample used for the measurement of water absorption.

- value of water absorption obtained for each measurement (1, $15 \mathrm{~min}, 4,48 \mathrm{~h})$.

- diagram: time (log)/water absorption in [\%].

- Initial rate of absorption (IRA) which corresponds to $\mathrm{W}$ (1 min).

- $K_{l}$ which correspond to the slope of the curve W (t) as a function of logarithmic time.

- average value, standard deviation and coefficient of variation between the 3 measurements.

\subsection{Bulk density}

The measurement of bulk density consists in weighing aggregate and measuring the corresponding volume with water [1].

\subsubsection{Equipment required}

- Balances or scales, accurate to $\pm 0.1 \%$ of test portion mass.

- Small scoop.

- Cylindrical mould (glass or Plexiglas) $10 \mathrm{~cm}$ to $20 \mathrm{~cm}$ in diameter and at least twice the diameter in height to take sample of hemp shiv aggregates.

- Sealed bags.

- Cardboard disc.

- Ventilated oven, thermostatically controlled to maintain a temperature of $\left(60 \pm 5^{\circ} \mathrm{C}\right)$, or other suitable equipment for drying the bio-aggregates, provided it does not cause any particle size breakdown.

\subsubsection{Size of sample}

After sampling (Fig. 1), the quantity of the material for one measurement should be adjusted to be half the volume of the cylindrical mould intended to be used to measure the bulk density.

\subsubsection{Operating instructions}

1. Dry the material at $60{ }^{\circ} \mathrm{C}$ until constant mass is reached (variation less than $0.1 \%$ between two readings at $24 \mathrm{~h}$ ).

2. Place hemp shiv in a sealed bag or a sealed bucket until equilibrated with room temperature.

3. Weigh the empty cylindrical mould.

4. Put the dried material in the dry cylindrical mould. The quantity of the material should be adjusted to be half the volume of the cylinder.

5. Upend the cylinder ten times.

6. Shake to obtain a horizontal surface.

7. Place a cardboard disc on the surface of the shiv and mark the level on the cylinder.

8. Remove the shiv from the cylinder.

9. Fill the cylinder with water to the level of the mark.

10. Weigh the cylinder and calculate the volume of water.

11. Calculate the bulk density of the shiv. The bulk density of aggregate is calculated from 
the mass and the volume of the sample according Eq. 2:

$\rho=\frac{M}{V}$

where $\rho$ is the bulk density $\left[\mathrm{kg} / \mathrm{m}^{3}\right], \mathrm{M}$ is the mass $[\mathrm{kg}]$ and $\mathrm{V}$ is the volume $\left[\mathrm{m}^{3}\right]$ of the sample.

12. Repeat the test 3 times (with 3 different samples of shiv).

\subsubsection{Precision}

If the coefficient of variation is less than $5 \%$, the mean value is considered to be representative. If not, repeat the protocol again until the statistical test can be validated.

\subsubsection{Report}

The report should include:

- Identification of test sample.- date of test.

- Data related to the drying of the sample.

- Description of the protocol precising the size and the mass of the cylindrical mould.

- For each measurement: the mass of the sample, the mass of filling water, the calculated volume and the calculated bulk density.

- Average value, standard deviation and coefficient of variation between measurements.

\subsection{Particle size distribution}

The particle size distribution of bio-aggregate may be studied from sieving method and/or from image analysis [2].

\subsubsection{Sieving methods}

The test consists of dividing and separating a material into several particle size classifications of decreasing sizes by means of a series of sieves. The aperture sizes and the number of sieves are selected in accordance with the nature of the sample and the accuracy required.
4.5.1.1 Equipment required All sieving apparatus shall conform to the general requirements of EN 932-5

[7]. The equipment required is:

- Test sieves, with apertures shall be in accordance with EN 933-2 [8].

- Tightly fitting pan and lid, for the sieves.

- Ventilated oven, thermostatically controlled to maintain a temperature of $\left(60 \pm 5{ }^{\circ} \mathrm{C}\right)$, or other suitable equipment for drying the bio-aggregates, provided it does not cause any particle size breakdown.

- Balance or scales, accurate to $\pm 0.1 \%$ of test portion mass.

- Trays, brushes.

- Sieving machine (optional).

4.5.1.2 Size of sample After sampling (Fig. 1), a sample of $0.25 \mathrm{~kg}$ a hemp shiv is required for sieving method.

4.5.1.3 Operating instructions The test should be done laboratory at control temperature $21 \pm 2{ }^{\circ} \mathrm{C}$.

1. Dry the material at $60{ }^{\circ} \mathrm{C}$ until constant mass is reached (variation less than $0.1 \%$ between two weightings at $24 \mathrm{~h}$ ). A slight increase of sample mass during the test due may occur due to adsorption of humidity from the air. This increase will be a function of the test duration and the ambient relative humidity. To avoid this drawback, sieved fractions should be weighed with a very short time lapse after the sieving process.

Other tests could also be done at moisture equilibrium with the ambient conditions.

2. The mass of sample used should be $100 \pm 20 \mathrm{~g}$ of the in case of 300 or $315 \mathrm{~mm}$ diameter sieves and $45 \pm 10 \mathrm{~g}$ in case of 200 or $203 \mathrm{~mm}$ diameter sieves.

3. Spread out the shiv over the first sieve. The operating time should be about 30 min with 6-7 sieves maximum.

4. Weigh each sieve before and after sieving. The difference with initial empty sieve will give the corresponding retained fraction. Check if the sum 
of the retained masses corresponds to the initial input mass of material.

The nominal aperture of the last sieve should be set at $0.5 \mathrm{~mm}$ to evaluate the dust content.

The aperture ranging should be adjusted according to the sizes of the aggregate being studied.

\subsubsection{Image analysis method}

\subsubsection{Equipment required}

- Ventilated oven, thermostatically controlled to maintain a temperature of $\left(60 \pm 5^{\circ} \mathrm{C}\right)$, or other suitable equipment for drying the bio-aggregates, if it does not cause any particle size breakdown.

- Balance or scales, accurate to $\pm 0.1 \%$ of test portion mass.

- Scanner.

- Computer.

- Software ImageJ or similar.

4.5.2.2 Size of sample After Sampling (Fig. 1), a sample of 3-6 g of hemp shiv is required for sieving method.

\subsubsection{Operating instructions}

1. Sample of 3-6 g should be studied in order they include at least 2000 identified particles that cover more than 100 pixels (i.e.: with an area greater than $0.18 \mathrm{~mm}^{2}$ at 600 dpi resolution).

2. A commonly available flatbed scanner can be used (it is cheap and convenient). It avoids image distortion and ensures repetitive calibration. 8-bit gray scale image with 600 dpi (dot per inch) definition appears to be a good compromise.

3. Use a dark background in order to obtain the maximum contrast. Particles can be laid and stuck on a black sheet using a glue spray, or directly laid on the glass of scanner. Spread the particles in a manner that they do not touch or overlap one another.

4. Use Image (or equivalent software) to analyse the images. (NB guidelines and user manual are available online).

- Setting the appropriate threshold is a crucial step that needs to be adjusted to obtain the most representative binary image, i.e. the binary image should match the original image of real particles as closely as possible.

5. Save the results file and provide the following information:

- Accurate mass of the sample analysed (at moisture equilibrium with ambient conditions).

- Method used to obtain the pictures and resolution of images.

\subsubsection{Report}

The report should include:

- Identification of test sample.

- Total number of identified particles.

- Chosen scale (i.e. size of pixel) and at least the following information for each identified particle: projected area and perimeter; length of major and minor axis of fitted ellipse and/or the Feret diameters (min. and max. calliper).

- Shape parameters such as the solidity ratio are useful to detect the non-convex particle portion that may induce bias in width estimation [2].

- Optionally, circularity or roundness parameters can be used to make more detailed analysis.

- Sieving results are usually based on size gradation, i.e. on cumulative percentage passing by weight. But such graphical representation of PSD obtained by image analysis should consider similar distribution for both length and width of particles, which can depart strongly since particle can be significantly elongated. Since weight distribution cannot be directly assessed with 2D image analysis, many ways can be used to plot the results of image analysis in order to relevantly compare the size distributions.

1. Frequency distribution, denoted as $\mathrm{N} \%$ in Fig. 3, is very sensitive to size of the smallest particle. It is inappropriate in case of shiv as in most of cases dealing with natural granular material, i.e. when the range of size is wide and the smallest particles are numerous [2, 4].

2. Area based distribution, denoted as $\mathrm{A} \%$ in Fig. 3, can be directly assessed from the data results. Considering 2D image analysis, it is probably the best method to characterize the PSD even the results cannot be directly 
Fig. 3 Plotting of cumulative distributions of lengths and widths deduced from 2600 analysed hemp shiv particles and comparison with results obtained from mechanical sieving with corresponding error bars, according to the square aperture of sieve, $d$, and to the diagonal of the square aperture $\left(2^{1 / 2} \mathrm{~d}\right)$

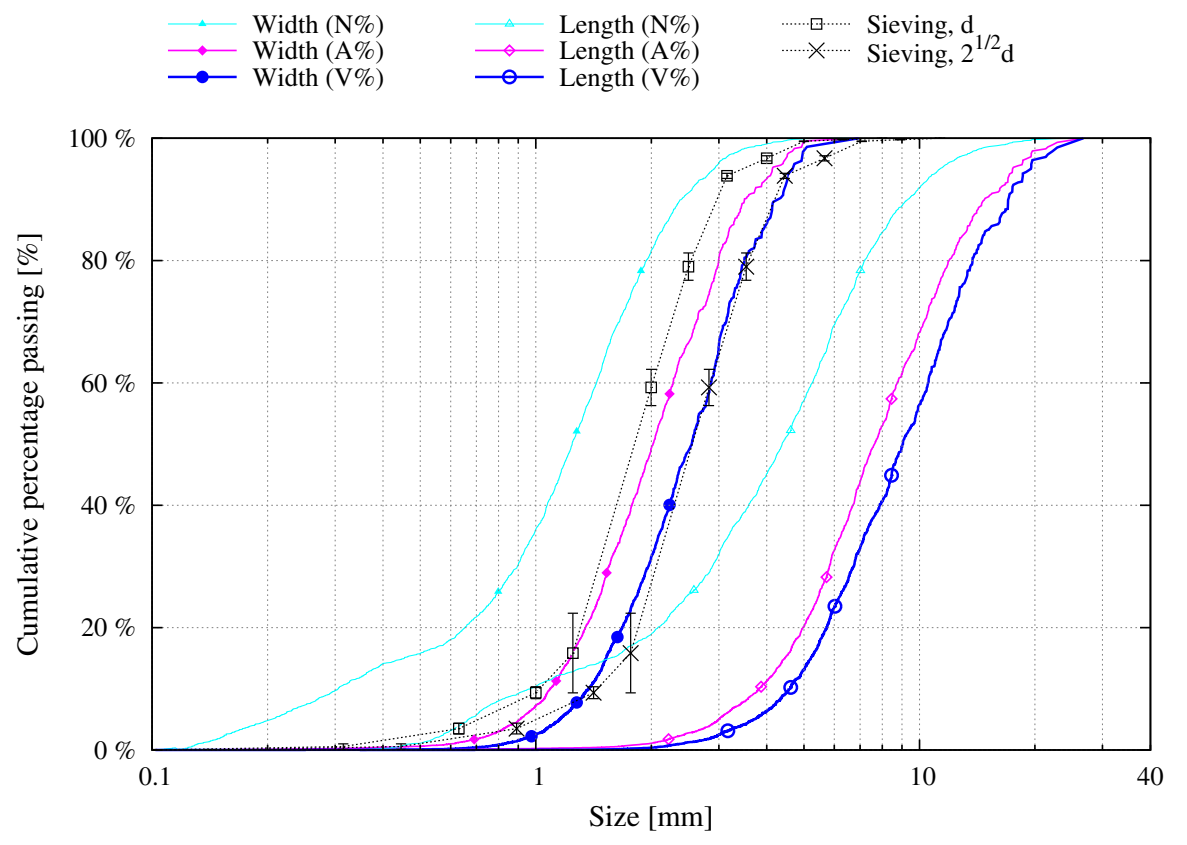

compared to those obtained with mechanical sieving [2].

3. Volume fraction distribution, denoted as V\% in Fig. 3, can be approached if the relationship between length, or width, and thickness of particles is known. Basically, a constant ratio between these dimensions can be assumed, leading to consider particles with homothetic shape [4]. In such a case, if the density of particles is assumed independent of the size, the volume distribution can be relevantly compared to the weight distribution obtained by mechanical sieving. For instance, the "volume" gradation of widths of hemp shiv corroborates the sieving "mass" gradation considering the size of the diagonal square aperture $\left(2^{1 / 2} d\right)$ [4]. Moreover, knowing the mass and the density of the whole analysed particles, the mean flatness of particles can be estimated by such method [1].

- In case of shiv coming from a comminution process, the gradation of particle size, as shown in Fig. 3, usually shows uni-modal distributions for both particle width and length. The log-normal distribution models provide adequate and robust fits. As a consequence, the weighted geometric mean, $X_{g m}$, and its associated standard deviation, $\sigma_{g m}$, directly computed from data results, appear to be relevant parameters to characterise the considered size distribution [2].

\subsection{Thermal conductivity}

The thermal conductivity can be measured in dry state or in a humid state [3].

For dry state, either hot plate or hot wire can be used to measure thermal conductivity. For humid state, hot wire is better. The hot plate induces moisture migration altering the repeatability of the measure.

\subsubsection{Equipment description}

For sample conditioning, the optimal method consists in the use of a container of known volume to control density during measurement (Fig. 4). An overall view of the thermal conductivity equipment is shown in Fig. 4.

\subsubsection{Size of the sample}

One single thermal conductivity test of hemp shiv requires a minimum volume of approximately 21 (around $200 \mathrm{~g}$ ). 

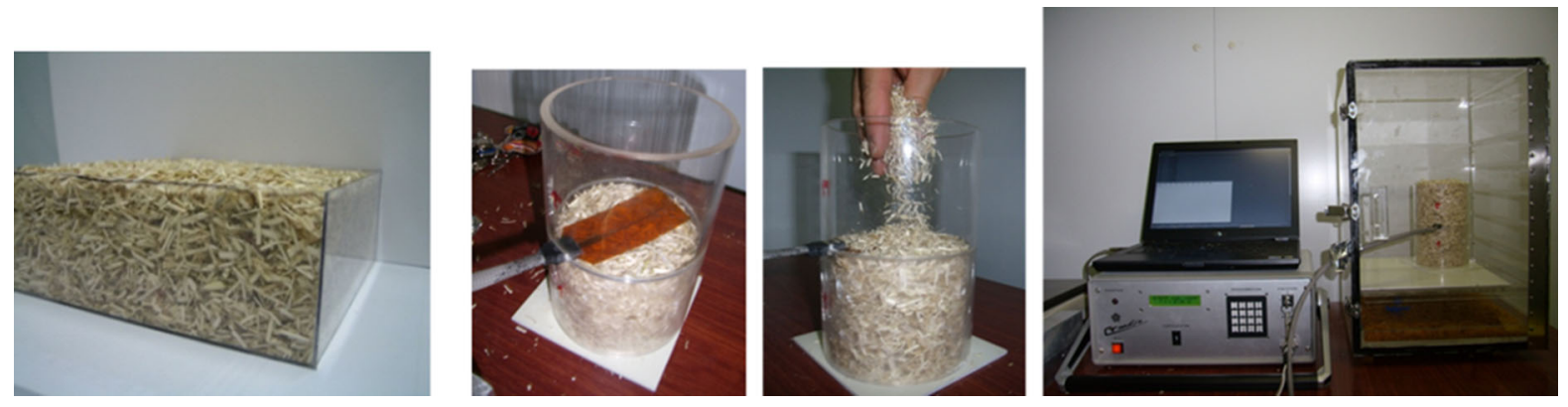

Fig. 4 Examples of devices to control density during measurement (left: guarded hot plate, right: hot wire)

\subsubsection{Operating instructions}

1. Dry the material at $60{ }^{\circ} \mathrm{C}$ until constant mass is reached (variation lower than $0.1 \%$ between two weightings at $24 \mathrm{~h}$ ).

2. Put the hemp shiv in a sealed bag or a sealed bucket until equilibrated with room temperature.

(A) Hot plate method

3. To measure thermal conductivity with hot plate, the minimum thickness is $4.5 \mathrm{~cm}$ and the minimum lateral length is twice the thickness.

4. The bulk density must be measured: hemp shiv is placed in a known volume. Hemp shiv is weighed before and after the measurement.

5. The measurement is held once a steady state is considered to be reached (when the change in conductivity is less than $1 \%$ in $60 \mathrm{~min}$ ).

6. The gradient of temperature should be given.

7. Repeat the test 3 times (with 3 different samples of shiv).

(B) Hot wire

3. Hemp shiv particles are placed in a container to measure bulk density.

4. The power of hot wire should be between 0.1 and $0.2 \mathrm{~W}$. The duration of the measurement should be between 60 and $120 \mathrm{~s}$.

5. Repeat the test 5 times (with 5 different samples of shiv).

\subsubsection{Precision}

If the coefficient of variation is less than $5 \%$, the mean value is considered to be representative. If not, repeat the protocol again until the statistical test can be validated.

\subsubsection{Report}

The report should include:

- Identification of test sample.

- Data related to the drying of the sample.

- Description of the protocol with parameters:

1. for hot plate: temperature gradient and duration of the test.

2. for hot wire: heating power and duration of the measurement.

- Description of the device giving the size of the sample and its volume.

- Bulk density of shiv in a dry state and the bulk density of the sample used for the measurement of thermal conductivity.

- Mass of shiv before and after measurement of thermal conductivity.

- Value of thermal conductivity obtained for each measurement.

1. with temperature gradient and correlation coefficient for hot plate.

2. with temperature increase and correlation coefficient for hot wire.

- Average value, standard deviation and coefficient of variation between measurements. 


\section{Compliance with ethical standards}

Conflict of interest The authors declare that they have no conflict of interest.

\section{References}

1. Amziane S, Collet F, Lawrence M, Magnion C, Picandet V (2017) Round robin test for hemp shiv characterisation: part 1 Evaluation of initial water content and water absorption. In: Amziane S, Collet F (eds) Bio-aggregates based building materials: state of the art report of 236 TC bio based building materials. Springer. doi:10.1007/978-94-024-1031-0

2. Amziane S, Collet F, Lawrence M, Magnion C, Picandet V (2017) Round robin test for hemp shiv characterisation: part 2 Bulk density and particle size distribution. In: Amziane S, Collet F (eds) Bio-aggregates based building materials: state of the art report of $236 \mathrm{TC}$ bio based building materials. Springer. doi:10.1007/978-94-024-1031-0
3. Amziane S, Collet F, Lawrence M, Magnion C, Picandet V (2017) Round robin test for hemp shiv characterisation: part 3 Thermal conductivity. In: Amziane S, Collet F (eds) Bioaggregates based building materials: state of the art report of 236 TC bio based building materials. Springer. doi:10.1007/ 978-94-024-1031-0

4. Amziane S, Arnaud L (2013) Bio-aggregate-based Building Materials: Applications to Hemp Concretes. Ed. Wiley-ISTE

5. Amziane S, Sonebi M (2016) Overview on Biobased Building Material made with plant aggregate. Rilem Tech Lett 1:31-38

6. Amziane S, Sonebi M (2014) In: Proceedings of the First International Conference on "Bio-Based Building Materials", ICBBM-2-15, Proceedings PRO 99, Ed. Amziane, S., Sonebi, M., Clermont-Ferrand (France) RILEM Publications s.a.r.1., 746 p. e-ISBN: 978-2-35158-154-4

7. EN 932-5:2012-Tests for general properties of aggregates. Common equipment and calibration

8. EN 933-2:1996, Tests for geometrical properties of aggregates. Determination of particle size distribution. Test sieves, nominal size of apertures 